\title{
Radiofrequency for the treatment of skin laxity: mith or truth*
}

\author{
Angélica Rodrigues de Araújo ${ }^{1}$ \\ Fernanda Souza da Silva ${ }^{3}$
}

\author{
Viviane Pinheiro Campos Soares ${ }^{2}$ \\ Tatiane da Silva Moreira ${ }^{4}$
}

\begin{abstract}
The nonablative radiofrequency is a procedure commonly used for the treatment of skin laxity from an increase in tissue temperature. The goal is to induce thermal damage to thus stimulate neocollagenesis in deep layers of the skin and subcutaneous tissue. However, many of these devices haven't been tested and their parameters are still not accepted by the scientific community. Because of this, it is necessary to review the literature regarding the physiological effects and parameters for application of radiofrequency and methodological quality and level of evidence of studies. A literature search was performed in MEDLINE, PEDro, SciELO, PubMed, LILACS and CAPES and experimental studies in humans, which used radiofrequency devices as treatment for facial or body laxity, were selected. The results showed that the main physiological effect is to stimulate collagen synthesis. There was no homogeneity between studies in relation to most of the parameters used and the methodological quality of studies and level of evidence for using radiofrequency are low. This fact complicates the determination of effective parameters for clinical use of this device in the treatment of skin laxity. The analyzed studies suggest that radiofrequency is effective, however the physiological mechanisms and the required parameters are not clear in the literature.
\end{abstract}

Keywords: Esthetics; Radio waves; Rejuvenation; Skin aging

\section{INTRODUCTION}

In recent years, concern with body has gained much importance in society, because beauty is reflected in self-esteem and quality of life. ${ }^{1}$ This fact contributed to the growth of the search for beauty treatments.

Among the unesthetic disorders, laxity, especially in the skin, is one that has great impact on the function and quality of life. ${ }^{2}$ A lax tissue is the result of biomolecular changes, and the damage due to collagen fibers change is closely involved in this process. ${ }^{3}$

Currently, there are several strategies, invasive and non-invasive, to treat unesthetic disorders. ${ }^{4,5}$ Despite relatively better results of invasive treatments, the sequelae and the complications that may be caused by them lead to increasing search for non-invasive or minimally invasive procedures. ${ }^{6,7}$

Among the non-invasive procedures, those that use electromagnetic fields (EMF) to directly or indirectly influence cells stand out. ${ }^{8,9}$ Nonablative radiofrequency $(\mathrm{RF})$ is one of the commonly used procedures, especially for the treatment of skin laxity. This is a therapeutic modality that produces a selective and controlled rise in tissue temperature from a high frequency alternating current $(0.3$ to $10 \mathrm{MHz})$. The rising of temperature and the depth of heating depend on the level of energy used and on the impedance of biological tissues. ${ }^{10}$ The final goal is to induce thermal 
damage to stimulate changes in collagen conformation and produce neocollagenesis in deep layers of the skin and subcutaneous tissue. ${ }^{11}$ However, literature is not unanimous in relation to the occurrence of these benefits. $^{12}$

Controversies regarding nonablative $\mathrm{RF}$, beyond purely scientific discussions, also involve economic questions - i.e. market interests that, in the field of healthcare focused on esthetic, are very strong. This fact is evident when observing the explosion of RF equipment designed for beauty treatments in the market (national and international). Many of these devices have not yet tested parameters and they aren't accepted by the scientific community, which may represent a serious risk to the user's health. ${ }^{13}$ Therefore, it is necessary to review the literature regarding the physiological effects, the appropriate parameters for the use of nonablative RF and the methodological quality and level of evidence of the studies. Additionally, analysis of the equipment available on the market allows the performance of safe and effective applications in the clinical practice.

\section{METHODOLOGY}

\section{Search strategy}

A literature search was conducted from August 2013 to December 2013 in six databases (MEDLINE, PEDro, SciELO, PubMed, LILACS and CAPES), using the keywords "facial rejuvenation", "skin rejuvenation"," skin tightening"," laxity", "cutaneous remodeling", "body shaping", "body contouring", "skin contraction", "rhytides", "radiofrequency non-ablative", "radiofrequency nonablative" and "radiofrequency non-invasive". In addition to the electronic databases, the search was supplemented by a manual search, which had the bibliography of previously selected articles as reference.

\section{Inclusion criteria \\ Type of study}

Experimental studies, published between January 2000 and December 2013, in English and Portuguese, which had full text, were included.

\section{Participants}

We selected studies carried out on humans, both sexes, diagnosed as facial or body laxity.

\section{Intervention}

Studies that used nonablative RF devices as treatment for facial or body laxity were included. Studies that used other associated therapies were included only if the effect of nonablative RF could be identified separately.

\section{Exclusion criteria}

Studies in animals or that used combination therapy or ablative RF as a treatment for skin laxity were excluded from the review.

\section{Data extraction}

Four independent reviewers selected the articles by title and abstract. If this provided enough information for inclusion, a complete copy of the text was requested. In the presence of differences between examiners, these get together to reach a consensus. If the disagreement remained, a fifth person was invited to address the problem.

Characteristics, methodological quality and level of evidence of studies

Selected studies were organized into a table for the general characterization of the study and facilitating of the analysis of methodological quality and level of evidence. Data regarding objective, sample size, study groups, analyzed endpoints, measuring instruments, obtained results and justification for the study were gathered.

For the assessment of the methodological quality of the articles we used PEDro scale ${ }^{14}$ (Physiotherapy Evidence Database) and to analyze the level of evidence we used the criteria proposed in the work of Reid and Rivett (2005), adapted for this study. ${ }^{15}$

\section{Treatment parameters}

Data related to the treated area, technical specifications of equipment used, parameters (frequency, power and temperature) and treatment protocol were selected and analyzed.

\section{Market analysis}

We investigated the relationship between what is advocated in the literature for the use of nonablative $\mathrm{RF}$, comparing it with what is offered by nonablative RF equipment available in Brazil and abroad. It was observed that the equipment allow the adjustment of the parameters and techniques for safe and effective intervention. A survey in the instruction manual and/ or contact with the manufacturer was carried out to acquire the technical characteristics of the devices.

\section{RESULTS}

Literature search yielded a total of 139 articles. Of these, 62 were selected and 32 were excluded, remaining 31 studies for review. $6,12,16-44$

Characteristics, methodological quality and level of evidence of studies

Main characteristics of the studies are summarized in table 1. It's possible to note that the sam- 
ple used was composed predominantly by women $(95.17 \%)$, aged between 35 and 65 years. Most studies (96\%) had no control group, and only in Bassichis et al study (2004) the results were analyzed through a comparison with a control group..$^{20}$

Primary endpoint assessed in the studies was facial laxity $(61 \%)$, followed by wrinkles $(28 \%)$ and body laxity (11\%), evaluated in the arms, abdomen, thighs and buttocks. To analyze the endpoints, pictures (face laxity: 51\%; wrinkles: 52\%; body laxity: $50 \%$ ), customer satisfaction questionnaire (face laxity: $27 \%$; wrinkles: $23 \%$; body laxity: $25 \%$ ), Fitzpatrick scale (face laxity: 7\%; wrinkles: $9 \%$ ), forehead height measurement (face laxity: $4 \%$ ) and biopsy (face laxity: $3 \%$; wrinkles: $14 \%$; body laxity: $25 \%$ ) were used.

Although majority of studies (96\%) report positive results in treating skin laxity using RF, only $44 \%$ showed statistical significance. In other studies, results were described quantitatively. In $100 \%$ of these studies, authors explained the results by positive thermal effects caused by RF.

All reviewed articles reached grade $\leq 4$ on PEDro scale. ${ }^{14}$ Main problems were lack of control group $(96 \%)$, no secret allocation $(100 \%)$ and no blinding of subjects, therapists and evaluators $(100 \%)$. On the analysis of level of evidence, it was observed that $88 \%$ of the studies presented limited methodological quality, suggesting insufficient scientific evidence of the benefits of nonablative RF regarding skin laxity.

\section{Physiological effects}

The main physiological effects observed in the studies were the contraction of collagen (short-term effect) and the stimulation of collagen synthesis through the tissue repair process (long-term effect).

\section{Parameters of study treatment}

The most used equipment was Thermacool (THERMAGE), used in 52\% of trials. Regarding the frequency of electromagnetic waves, there was a wide divergence. However, there is a tendency to use 6 $\mathrm{MHz}$ frequency, observed in $64 \%$ of trials.

The thermal power was the parameter that showed more divergence. Forty-six percent of the studies used the maximum power of $330 \mathrm{~W} ; 25 \%$ did not mention the power used or data as application time and size of the nozzle that would enable the calculation thereof. In other studies there was great variation of this parameter. No study measured the temperature in RF therapeutic target, the dermis, and the values were measured only in the epidermis. Sixty-four percent of reviewed studies maintained the temperature range in the epidermis between $35^{\circ} \mathrm{C}$ and $45^{\circ} \mathrm{C}$ and $36 \%$ didn't measure the temperature range.

Regarding the treatment time, it was observed that there was no standardization, ranging from one to 24 weeks. There was, however, a tendency toward only one session $(25.92 \%)$. In $18.5 \%$ of the studies, the treatment time was not specified.

The area (face or body), and the processing parameters used in each study are summarized in table 2 .

\section{Market analysis}

Analyzing RF equipment available in the market, both in Brazil and abroad, a great variability in relation to the parameters offered by the equipment and the modulation range of these parameters can be observed, especially in relation to the frequency of electromagnetic waves and the thermal power. Not all devices provide in their manuals data or technical specifications of the radiation used, and even after contact by e-mail it was not possible to have access to this information.

Most of the devices found on the market are international. ${ }^{45-56}$ According to information collected in the respective manuals and websites of manufacturers, the frequency varies from $1 \mathrm{MHz}$ to $6 \mathrm{MHz}$ and the power ranges from $40 \mathrm{MHz}$ to $240 \mathrm{~W}$. Most of these equipment allows power settings according to the treated area. RF application in each region takes about 2.5 seconds. Manuals also mention that, during the treatment, the temperature in the epidermis is maintained at $40^{\circ} \mathrm{C}$, whereas in the dermis it ranges from $50^{\circ} \mathrm{C}$ to $75^{\circ} \mathrm{C}$. The form of energy transmission to the tissue is through the capacitive method, with bipolar, tripolar or multipolar electrodes. The main side effect is pain during treatment, and to minimize it the patient receives a topical and/or oral anesthetic.

In Brazilian RF devices, according to their respective manuals and manufactures websites, the frequency, in most of equipments, varies between 0.64 $\mathrm{MHz}$ and $8 \mathrm{MHz}$, and 1 device works with the frequency of $27.12 \mathrm{MHz} .{ }^{57-63}$ The power used ranges from $50 \mathrm{~W}$ to $150 \mathrm{~W}$ - lower than the international equipment and without the possibility of adjustment during treatment. Treatment time ranges from 5 to 10 minutes per unit area $\left(10 \mathrm{~cm}^{2}\right.$ quadrants $)$ and the temperature is maintained at $40^{\circ} \mathrm{C}$ in the epidermis. According to the manuals, in the dermis the temperature is around $60^{\circ} \mathrm{C}$ and the treatment is painless, with no the need for using anesthetics. Despite this statement of manufacturers, in clinical practice it is possible to note that the application of RF is not completely painless and discomfort can be felt due to the temperature rise. The form of energy transmission to the tissue is through capacitive method (bipolar, tripolar or multipolar electrodes) in most equipments; two equipments ${ }^{59,63}$ use inductive method (monopolar electrode). ${ }^{57,59-63}$

Characteristics of the equipment on the market are summarized in table 3 . 
TABLE 1: Characteristics of studies selected for research

\begin{tabular}{llll}
\hline Author/ year & Objective & Sample / Groups & Endpoint variable \\
\hline 1. Shapiro et al., 2012 & $\begin{array}{l}\text { To evaluate the effectiveness of RF for the } \\
\text { treatment of wrinkles. }\end{array}$ & $\begin{array}{l}37 \text { subjects/ women/ } 36 \text { a } 65 \text { years. } \\
\text { (No control group) }\end{array}$ & Wrinkles. \\
2. Abrahan et al., 2004 & $\begin{array}{l}\text { To evaluate the effectiveness of RF for the } \\
\text { treatment of wrinkles and laxity. }\end{array}$ & $\begin{array}{l}35 \text { subjects/ 28 women and } 7 \text { men/ } 35 \\
\text { to 65 years.(no control group) }\end{array}$ & Wrinkles and laxity.
\end{tabular}

3. Rusciani et al., $2007^{18}$

4. Hsu et al.,2003 ${ }^{19}$

5. Harth et al., $2010^{12}$

6. Bassichis et al., $2004^{20}$

7. Lee et al., $201^{16}$

8. El-Domyati et al., $2011^{21}$

9. Javate et al., $2011^{22}$

10. Friedman et al., $2007^{23}$

11. Fitzpatrick et al., $2003^{24}$

12. Alster et al., $2004^{25}$

13. Carruthers and Carruthers, $2007^{26}$

14. Finzi and Spangler, $2005^{27}$

15. Kushikata et al., $2005^{28}$

16. Levenberg, $2010^{29}$
To evaluate the effectiveness of RF for the treatment of laxity.

To evaluate the effectiveness of RF for the treatment of laxity.

To evaluate the effectiveness of RF for the treatment of laxity.

To evaluate the effectiveness of RF for the treatment of laxity.

To evaluate the effectiveness of RF signals in photoaging (wrinkles, pigmentation, telangiectasia, laxity)

To evaluate the effectiveness of RF for the treatment of wrinkles.

To evaluate the effectiveness of RF for the treatment of wrinkles.

To evaluate the effectiveness of RF for the treatment of wrinkles and laxity.

To evaluate the effectiveness of RF for the treatment of wrinkles and laxity.

To evaluate the effectiveness of RF for the treatment of wrinkles and laxity.

To evaluate the effectiveness of RF for the treatment of laxity.

To evaluate the effectiveness of RF for the treatment of laxity and wrinkles.

To evaluate the effectiveness of RF for the treatment of laxity.

To evaluate the effectiveness of RF for the treatment of laxity, wrinkles and fat.
93 subjects/ 83 women and 10 men/ mean 53,3 years.(no control group)

16 subjects/ 15 women and 1 men/ 43 Laxity. to 73 years(no control group)

30 subjects/ gender not mentioned/ age not mentioned (no control group)

36 subjects/ experimental group: 24 (23 women and 1 men; control group: 12 (gender not mentioned)/ age not mentioned

26 subjects/ 26 women/ mean 56 years(No control group)

6 subjects/ 6 women/ 47 to 62 years (No control group)

32 subjectså/ 28 women and 4 men/ 29 to 71 years (no control group)

16 subjects/ 16 women/ 29 to 66 Wrinkles and laxity. years (No control group)

86 subjects/ 79 women and 7 men/ 35 Wrinkles and laxity. to 70 years (no control group)

50 subjects/ gender not mentioned/ Wrinkles and laxity. mean 53,3 years(No control group)

20 subjects / 17 women and 3 men/ age not mentioned (No control group)

25 subjects/ 24 women and 1 men/ 33 Laxity and wrinkles. to 68 years (no control group)

85 subjects/ 85 women/ 31 to 68 Laxity. years (no control group)

37 subjects/ women/ 23 to 82 years (No control group)
Wrinkles.

Elastin and collagen quantity.

Wrinkles. Collagen quantity.

Laxity.

Wrinkles, Laxity and localized fat. 
TABLE 1: Characteristics of studies selected for research

\begin{tabular}{llll}
\hline Instrument & Result & Justification & PEDro/ Level of evidence
\end{tabular}

1. Pictures. $\quad$ Decrease in wrinkles.

Positive statistical difference.

2. Objective measurement of forehead height. Satisfaction questionnaire. Pictures.

3. Pictures.

4. Pictures. Satisfaction questionnaire.

5. Pictures. Fitzpatrick scale.

6. Satisfaction questionnaire. Pictures.

Brow's measurement.

7. Pictures. Medical evaluation. Scale of subjective improvement. Patient satisfaction

8. Pictures. Skin biopsy.

9. Pictures.

Patient satisfaction. Histological analysis. Fitzpatrick scale

10. Pictures.

11. Pictures.

Patient satisfaction. Fitzpatrick scale.

12. Pictures. Patient satisfaction.

13. Pictures. Patient satisfaction.

14. Pictures.

15. Pictures.

16. Pictures. Circumference measurements.
Decrease in wrinkles and laxity. Positive statistical difference.

Decrease in skin laxity. Positive statistical difference.

No significant change.

No statistical analysis.

Decrease in skin laxity. Positive statistical difference.

Forehead height reduction. Positive statistical difference. Client dissatisfaction.

Decrease in laxity, increased brightness and skin elasticity.

Positive statistical difference.

Decrease in wrinkles and increased collagen

Positive statistical difference.

Decrease in wrinkles.

Positive statistical difference.

Decrease in wrinkles and laxity.

Positive statistical difference.

Decrease in wrinkles and laxity.

No statistical analysis.

Decrease in wrinkles laxity.

No statistical analysis.

Decrease in laxity.

No statistical analysis.

Decrease in wrinkles and laxity. No statistical analysis.

Decreased laxity.

No statistical analysis.

Decreased laxity, wrinkles and localized fat. Positive statistical difference.
Thermal effect leads to production of collagen.

Thermal effect leads to production of collagen.

Thermal effect leads to production of collagen.

Thermal effect leads to production of collagen.

Thermal effect leads to production of collagen.

Thermal injury leads to the production of collagen .

Thermal injury .

Thermal effect leads to production of collagen.

Thermal effect leads to production of collagen.

Thermal effect leads to production of collagen.

Thermal effect leads to production of collagen.

Thermal effect leads to production of collagen.

Thermal effect leads to production of collagen.

Thermal effect leads to production of collagen.

Thermal effect leads to production of collagen.
2/ Insufficient evidence.

3/ Insufficient evidence.

2/ Insufficient evidence.

3/ Insufficient evidence.

2/ Insufficient evidence.

3/ Insufficient evidence.

4/ Limitada evidência.

2/ Insufficient evidence.

2/ Insufficient evidence.

2/ Insufficient evidence.

4/ Limitada evidência.

3/ Insufficient evidence.

4/ Limitada evidência.

3/ Insufficient evidence.

3/ Insufficient evidence. 
TABLE 1: Characteristics of studies selected for research

CONTINUED

\begin{tabular}{llll}
\hline Author/ year & Objective & Sample/Groups & Endpoint variable \\
\hline 17. Montesi et al., 200730 & $\begin{array}{l}\text { To evaluate the effectiveness of RF for the } \\
\text { treatment of laxity. }\end{array}$ & $\begin{array}{l}30 \text { subjects/ 26 women and } 4 \text { men/ 18 } \\
\text { to 70 years (no control group) }\end{array}$ & $\begin{array}{l}\text { Laxity and wrinkles } \\
\text { and collagen quantity. }\end{array}$
\end{tabular}

18. Nahm et al., $2004^{31}$

19. Narins and Narins, $2003^{32}$

20. Ruiz-Esparza and Gomez, $2003^{33}$

21. Uwe Wollina, $2011^{34}$

22. Bogle et al., $2007^{35}$

23. Fritz et al., $2004^{36}$

24. Esparza et al., $2004^{37}$

25. Kaplan et al., $2009^{38}$

26. Chipps et al., $2013^{39}$

27. Edwards et al., $2013^{40}$

28. Suh et al.,2013 ${ }^{41}$

29. Taub et al., $2012^{42}$

30. Tay and Kwok, $2009^{43}$

31. Vega et al., $2013^{44}$
To evaluate the effectiveness of RF for the treatment of laxity.

To evaluate the effectiveness of RF for the treatment of laxity.

To evaluate the effectiveness of RF for the treatment of laxity.

To evaluate the effectiveness of RF for the treatment of laxity.

To evaluate the effectiveness of RF for the treatment of laxity.

To evaluate the effectiveness of RF for the treatment of laxity.

To evaluate the effectiveness of RF for the treatment of laxity and wrinkles.

To evaluate the effectiveness of RF in fat reduction and collagen regeneration.

To evaluate the effectiveness of RF for the treatment of laxity and wrinkles.

To evaluate the effectiveness of RF for the treatment of laxity.

To evaluate the effectiveness of RF for the treatment of laxity and wrinkles

To evaluate the effectiveness of RF for the treatment of laxity and wrinkles.

To evaluate the effectiveness of RF for the treatment of laxity and wrinkles.

To evaluate the effectiveness of RF for the treatment of laxity.
10 subjects/ 9 women and 1 men/ 39 Laxity.

to 62 years(no control group)

17 subjects/ 17 women/ 42 to 60 years Laxity.

(No control group)

15 subjects/ 15 women/ 41 to 68 years Laxity.

(No control group)

20 subjects/ 20 women/ 34 to 73 years Laxity. (No control group)

66 subjects/ 66 women/ mean 35 Laxity. years. (No control group)

20 subjects/ 20 women/ 40 to 63 Laxity. years. (No control group)

20 subjects/ 20 women/ 42 to 67 Laxity and wrinkles. years. (No control group)

12 subjects/ 12 women/ 34 to 65 years. (No control group)

Laxity, localized fat and collagen quantity.

49 subjects/ 45 women and 4 men/ 30 Laxity and wrinkles. to 70 years.(no control group)

64 subjects(no control group)

Laxity.

8 subjects $/ 7$ women and 1 men

(No control group)

Laxity and wrinkles.

17 subjects/ gender not mentioned/ Laxity and wrinkles. age not mentioned.

(No control group)

6 subjects/ 6 women/ 30 to 60 years. Laxity and wrinkles.

(No control group)

31subjects/ 31 women/ 40 to 65 years Laxity.

(No control group) 
TABLE 1: Characteristics of studies selected for research

CONTINUED

\begin{tabular}{|c|c|c|c|}
\hline Instrument & Result & Justification & PEDro/Level of evidence \\
\hline $\begin{array}{l}\text { Pictures. } \\
\text { Patient satisfaction. } \\
\text { Biopsy. }\end{array}$ & $\begin{array}{l}\text { Decreased laxity. } \\
\text { No statistical analysis. }\end{array}$ & $\begin{array}{l}\text { Thermal effect leads to production of } \\
\text { collagen. }\end{array}$ & 3/ Insufficient evidence. \\
\hline
\end{tabular}

18. Pictures.

Patient satisfaction.

19. Pictures.

Patient satisfaction.

Decreased laxity.

Positive statistical difference.

Decreased laxity.

No statistical analysis.

20. Pictures.

21. Picture.

Patient satisfaction.

22. Pictures.

Laxity rating.

BTC2000 device (skin rigid-

ity and energy absorption).

23. Pictures.

24. Patient satisfaction. Quality of life questionnaires.

25. Pictures.

26. Pictures.

Patient satisfaction.

Quality of life questionnaires.

27. Pictures.

Patient satisfaction questionnaire.

28. Picture.

Pictures. Satisfaction questionnaire.

Glogau classification.

29. Pictures.

Satisfaction scale.

30. Pictures.

Patient satisfaction.

31. Pictures.

Global esthetic improvement.
Decreased laxity.

No statistical analysis.

Decreased laxity.

No statistical analysis.

Decreased laxity.

No statistical analysis.

Decreased laxity.

No statistical analysis.

Decreased laxity and wrinkles.

No statistical analysis.

Decreased laxity, localized fat and increased collagen

No statistical analysis.

Decreased laxity and das wrinkles.

Positive statistical difference.

Decreased laxity.

Decreased laxity.

No statistical analysis.

Decreased laxity and wrinkles. Positive statistical difference

Decreased laxity and wrinkles. No statistical analysis.

Decreased laxity.

No statistical analysis.
Positive statistical difference
Thermal effect leads to production of collagen.

Thermal effect leads to production of collagen.

Thermal effect leads to production of collagen.

Thermal effect leads to production of collagen.

Thermal effect leads to production of collagen.

Thermal effect leads to production of collagen.

Thermal effect leads to production of collagen.

Thermal effect leads to production of collagen.

Thermal effect leads to production of collagen.

Thermal effect leads to production of collagen.

Thermal effect leads to production of collagen.

Thermal effect leads to production of collagen.

Thermal effect leads to production of collagen.

Thermal effect leads to production of collagen.
3/ Insufficient evidence.

2/ Insufficient evidence.

3/ Insufficient evidence.

2/ Insufficient evidence.

3/ Insufficient evidence.

3/ Insufficient evidence.

2/ Insufficient evidence.

3/ Insufficient evidence.

2/ Insufficient evidence

2/ Insufficient evidence

2/ Insufficient evidence

3/ Insufficient evidence

2/ Insufficient evidence

2/ Insufficient evidence 


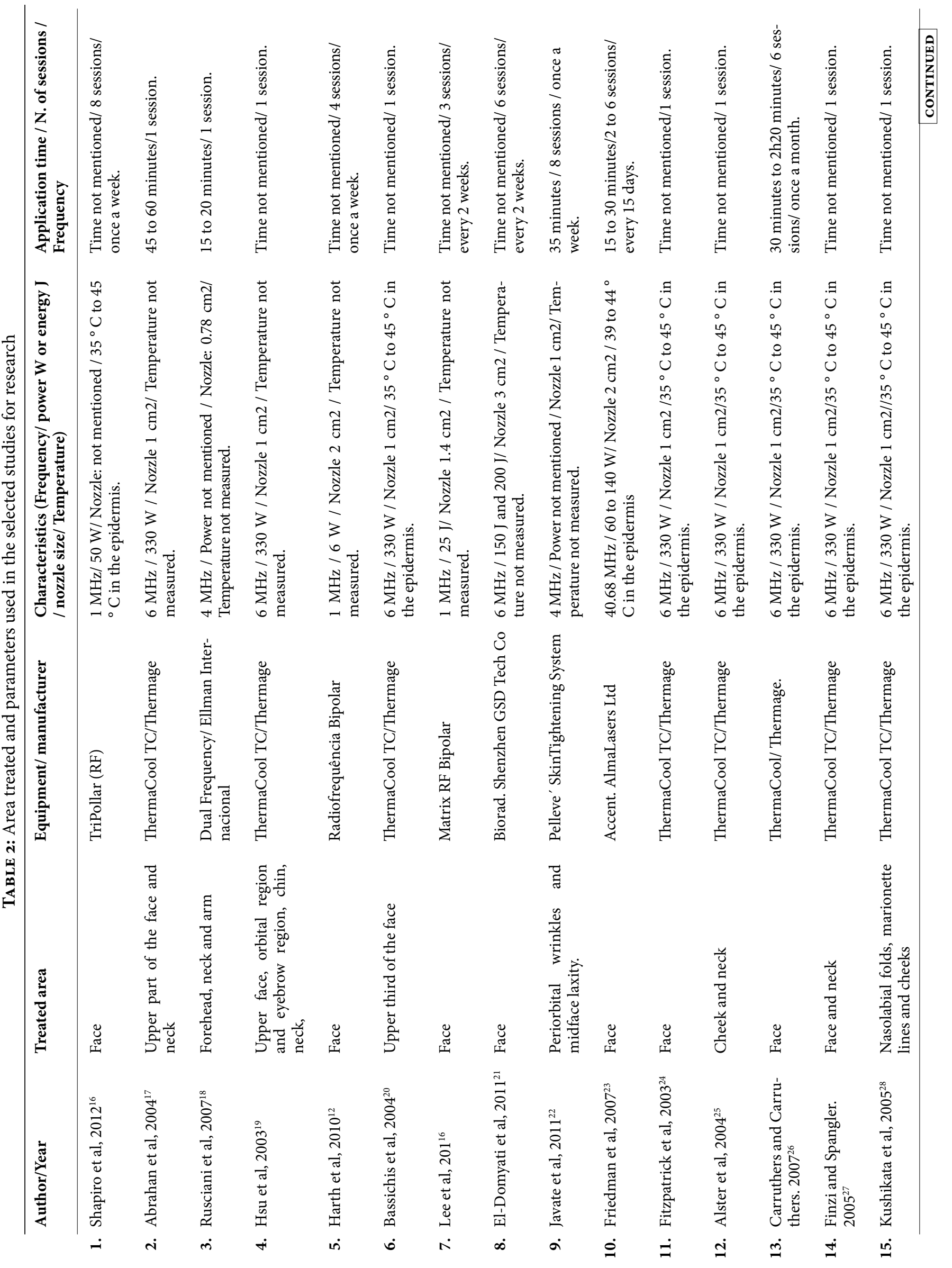




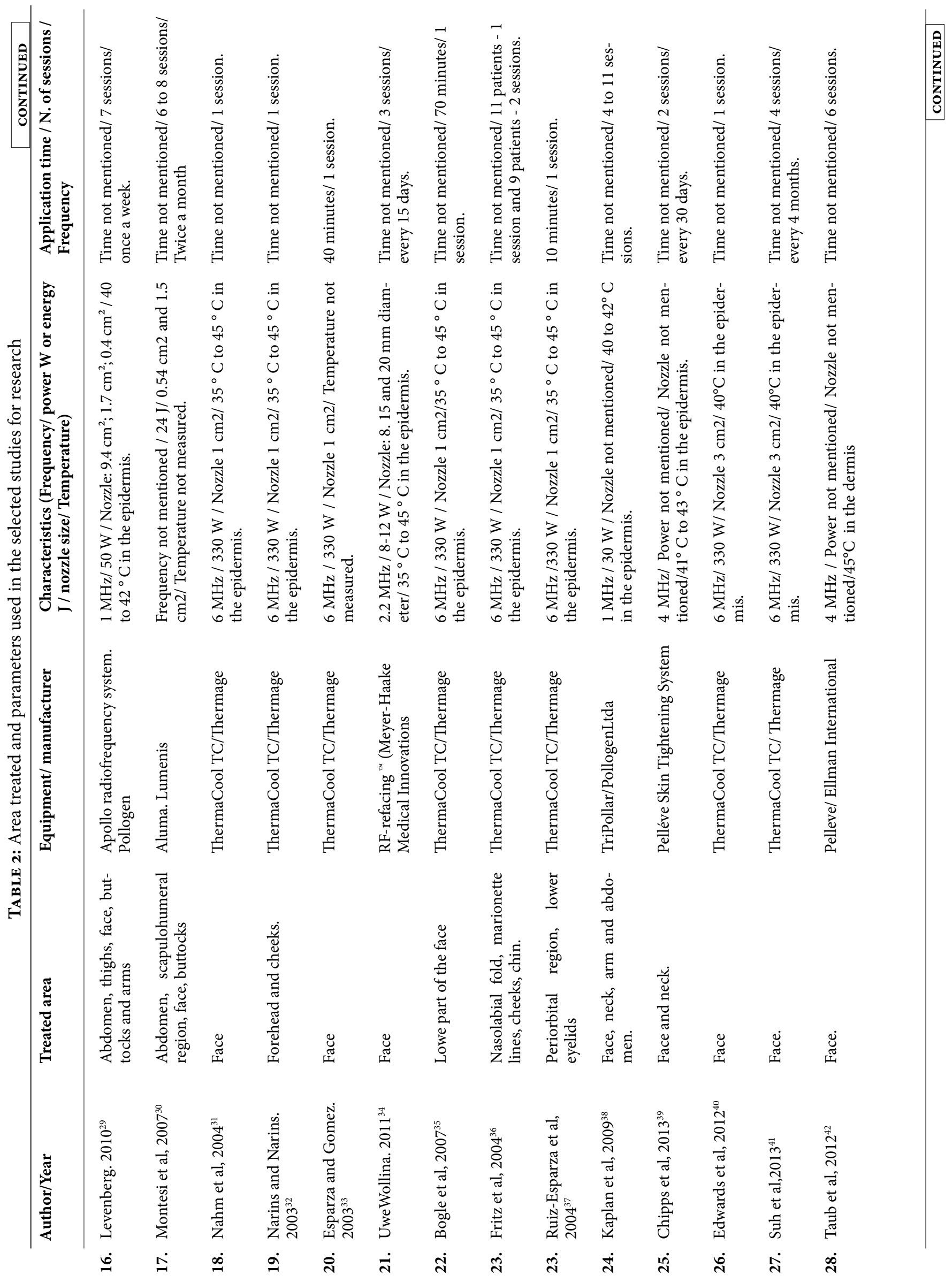



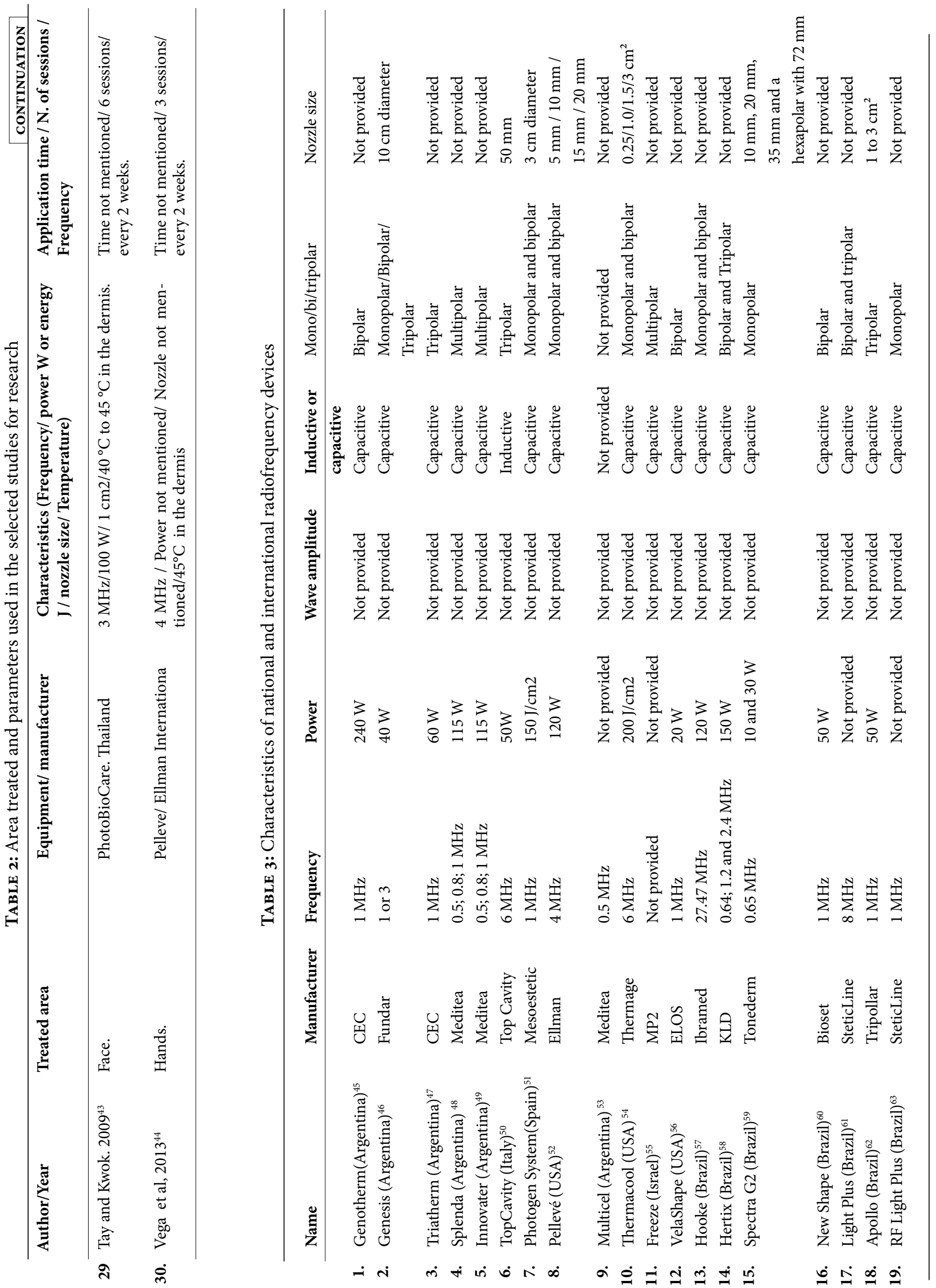


\section{DISCUSSION}

Skin aging may be divided into 2 processes: intrinsic and extrinsic aging or photoaging. The first is a natural, slow and gradual process. The second is exacerbated by environmental factors such as improper exposure to sunlight. Both are accompanied by changes in morphological and biomechanical properties of skin. ${ }^{64}$ The main clinical characteristics of aged skin are increased rugosity and loss of elasticity (laxity). Human dermis consists mostly of type I collagen, composed of 3 polypeptide chains stabilized by a triple-helical conformation. ${ }^{13}$ Using the microscope, it is observed that with age there is an increase of collagen network density and reduced stability of cross-links. ${ }^{13,65}$ Elastin, the main component of elastic fibers in the dermis, shows signs of decrease of its function, providing less resistance and traction capacity. Atrophy of subcutaneous fat is also noted..$^{65}$

Among the non-invasive procedures for treating skin wrinkles and laxity, RF is one of the most widely used. ${ }^{11}$ The objective of RF is to stimulate changes in collagen conformation and induce neocollagenesis by thermal power generation in deep layers of the skin and subcutaneous tissue. ${ }^{9}$

It was observed in this study that EMF can act on tissues in several ways, causing thermal and/or athermal effects. Several authors cite as thermal effects, caused by the increase of local tissue temperature, the contraction of collagen and the stimulus to the synthesis of collagen fibers. ${ }^{12,17,21,25}$ The literature also cites some athermal effects, where EMF could induce biological changes through interaction with cellular membrane receptors or channels. According to Bachl et al (2008) ${ }^{8}$, EMFs are able to stimulate the synthesis and cytoprotective growth factor. Goodman et al (2002) ${ }^{66}$ mention the increasing of enzyme activity, level of transcription of specific genes and mRNA expression. Tokalov et al (2004) ${ }^{67}$ reported, on their experiments with human cell cultures, that EMF leads to a significant induction of heat shock genes. Alvares et al (2008) ${ }^{68}$ also mention the effects on the synthesis of mucopolysaccharides and elastic fibers, which leads to dermal thickening, thus improving firmness and elasticity of the skin. In the studies reviewed, all authors credited the results observed only to the thermal effects caused by RF, without taking into account other actions promoted by EMF. However, only $12 \%$ of the studies used an objective instrument (biopsy) for establishing the therapeutic changes promoted by tissue heating, and most of the outcomes were evaluated through subjective data such as photographs or perception of the patient - very inaccurate measurements to validate the results. ${ }^{21,22,30,38}$

The reviewed literature mentions that RF for the treatment of skin laxity and wrinkles is founded on the use of a source of heat for denaturation of collagen (which occurs at temperatures ranging from $50^{\circ}$ $\mathrm{C}$ to $75^{\circ} \mathrm{C}$ in the dermis) and the consequent contraction of the connective tissue. ${ }^{9,10,69}$ These processes lead to tissue repair response, establishing long-term dermal remodeling. Zelickson et al (2004) demonstrated, through abdominal skin biopsies, than 8 weeks after the denaturation of collagen there is an induction of new collagen synthesis (neocollagenesis)..$^{70}$

According to Ruiz-Esparza et al (2003), the amount of synthesized collagen depends on the heating intensity of the connective tissue. ${ }^{33}$ Collagen protein is a compound of 3 polypeptide chains, which are involved in a triple helix structure. The process of thermal contraction of collagen begins with denaturing the triple helix, where the intramolecular crosslinks are broken and collagen undergoes a transition from a highly organized crystalline structure to a gellike state (denaturation). The collagen contraction occurs by the cumulative effect of the "unwinding" of the triple helix due to the destruction of intermolecular cross-links and the residual stress of such links. ${ }^{69}$ According to Ruiz-Esparza et al (2003), the thermal effects of RF can change the shape, the length and the diameter of the collagen fibers for the reorganization of collagen. ${ }^{33}$

In order to have an effective effect of RF in the treatment of skin laxity and wrinkles, it is vital to have knowledge not only of skin aging process, but also of parameters to be used, such as frequency and device power, treatment time and temperature maintained in the skin. Researches advocate the need for the use of appropriate parameters for the achievement of the therapeutic results of the RF, since the effects induced by EMFs are dependent parameters. ${ }^{8,71}$ This review observed that there is no report of standardization of the way to reference these parameters in the literature and, often, they are not made available from manufacturers of RF equipments.

Alvares et al (2008) studied changes in tissues, cells, thickness and structure of pigskin after each RF section and 2 months after the last application. ${ }^{68}$ The most significant changes were found 2 months after the last application. In biopsies taken after each session, it was observed that the papillary dermis was expanded due to edema and vascular congestion, followed by an accumulation of intercellular substance. In biopsies after 2 months of the last application, an increase in the amount of collagen, elastic fibers and mucopolysaccharides was noted.

The thermal power applied by the devices of the studies was the parameter that showed a greater difference. In $46 \%$ of the studies, the maximum power used was $330 \mathrm{~W}$, and in $29 \%$ it presented a great varia- 
tion of the adopted values. In other studies, the power was not mentioned or data that allowed the calculation of this variable were not provided, as well as application time or size of the nozzle used for treatment. Zelickson et al (2004) performed a dose-response study evaluating the efficacy of a RF device in the treatment of skin laxity in the abdominal area. ${ }^{70}$ Authors confirmed, by histological analysis, that using a power of $78 \mathrm{~W}$ showed significantly better results. There was a change in the areas of collagen fibers, with increased diameter and amount of type I collagen, after 8 weeks of treatment. Analysis of the power used is important since the conversion of electrical energy into thermal energy occurs due to the power supplied and the impedance of the tissue. ${ }^{72}$

The frequencies used in the reviewed studies ranged from $1 \mathrm{MHz}$ to $6 \mathrm{MHz}$, with the highest percentage of studies reporting a frequency of $6 \mathrm{MHz}$. According to Abraham and Mashkevich (2007) ${ }^{73}$, during the treatment cycle with an EMF at $6 \mathrm{MHz}$, it is determined that polarity alternates, at a rate of 6 million cycles per second, what stimulates the movement of charged particles and creates an electrical current within the tissue treated by attracting and repulsing electrons and ions. Through resistance of the tissue to this flow of particles occurs heat generation. ${ }^{11}$ The higher the frequency of EMF and the lesser vascularized the tissue, the greater will be the production of heat.

The literature reports that the penetration depth of RF is an inverse function of its frequency, that is, in lower frequencies $(0.8 \mathrm{MHz})$ occurs a greater penetration and in higher frequencies $(2.45 \mathrm{MHz})$, a lower penetration. ${ }^{10}$ Zelickson et al (2004) ${ }^{70}$ mention, however, that it is possible to change the depth of penetration of the treatment by changing the electrode geometry, the amount of power supplied and the duration of treatment.

The tissue temperature is another key parameter for achieving therapeutic goals with RF and is directly influenced by the characteristics of the tissue. ${ }_{11,74} \mathrm{RF}$ energy is conducted electrically to the tissue. Heat is generated when the inherent tissue resistance (impedance) to the passage of electrons converts the electric current to thermal energy. This reaction is determined by Ohm's Law: Energy $(J)=\mathrm{I}^{2} \times \mathrm{R} \times \mathrm{T}$ (where $\mathrm{I}=$ current, $\mathrm{R}=$ tissue impedance and $\mathrm{T}=$ time of application). High impedance tissues, such as subcutaneous fat, generate more heat. ${ }^{75}$ Several experiments with tendons, joint capsules and skins of different species (rat, bovine and human) have established that collagenous tissues suffer distortion when exposed to temperatures ranging from $65^{\circ} \mathrm{C}$ to $85^{\circ} \mathrm{C}$. ${ }^{76-78}$

In all the analyzed studies, the authors mention the need to reach high temperatures in the dermis in order to achieve therapeutic goals. In this review, how- ever, none of the authors measured the temperature of the therapeutic target, the dermis. There are reports on the temperature measurement in the epidermis, which remained around $40^{\circ} \mathrm{C}$ and $42^{\circ} \mathrm{C}$, and allusions on that in the dermis the temperature would be around 65 ${ }^{\circ} \mathrm{C}$. To date the application of RF viability with dermal heating and preservation of the epidermis was studied only by using a three-dimensional mathematical model. ${ }^{79}$ No scientific evidence of studies in humans that could reliably quantify the temperature of RF target was found. This fact undermines the decision-making and does not guarantee the effectiveness of treatment.

Some of the reviewed studies performed histological analyzes, whose findings show benefits of RF in increasing collagen production, thus reducing wrinkles and skin laxity. ${ }^{21,22,30} \mathrm{It}$ is noteworthy, however, that in the studies of Montesi et al (2007) ${ }^{30}$ and Kaplan et al $(2009)^{38}$ results were based only on quantitative data, with no statistical analysis.

Through the analysis of RF equipment available in the market it was revealed that international equipments, at first, seem to allow the modulation of parameters closer to those required to obtain significant changes in collagen. There aren't, in the surveyed databases, studies proving the effectiveness of Brazilian RF equipment, despite the benefits reported by manufacturers and the fact that these equipments are frequently found in clinics and medical offices in the country. Furthermore, by analyzing the manuals of these equipments, we observed that the power used is fixed and lower than that of international equipments used in the assessed studies. These data suggest that the physiological effects resulting from the use of RF can't be achieved with these equipments.

Regarding the frequency of electromagnetic waves, we noted a difference on the frequencies of the equipment used in the studies analyzed and those on the market (national and international). In studies with positive results there was a predominance of 6 $\mathrm{MHz}$ frequency, differently from the frequencies often cited in the manuals of equipments available on the market, which was $1 \mathrm{MHz}$. In one of the assessed equipments, the frequency reported by the manufacturer $(27.12 \mathrm{MHz})$ diverges from other equipments. ${ }^{47}$ Frequency of $27.12 \mathrm{MHz}$ is used in RF equipment commonly employed for the treatment of trauma and orthopedic disorders. In the manual of this equipment, this potency is justified by the demands made by international and national bodies, such as the Federal Communication Commission (FCC) and Agência Nacional de Telecomunicações (ANATEL), with the frequencies $13.56 \mathrm{MHz}, 27.12 \mathrm{MHz}$ and $40.68 \mathrm{MHz}$ designed for medical applications. However, there is no data to confirm benefits of these frequencies on skin laxity or wrinkles. 
Most equipment use capacitive method (bipolar, tripolar or multipolar electrode) for transmitting energy to the skin. According Montesi et al (2007) ${ }^{30}$, the main difference between the inductive and the capacitive method is the configuration of the electrodes to be applied to the skin, which will result in the way energy is transmitted to the tissues. The inductive method (monopolar electrode) uses an active and a passive electrode, the latter acting as a grounding electrode. Power is transmitted to the tissue via a single point of contact, which increases the penetration of the generated current. In the capacitive method (bipolar, tripolar or multipolar electrode), energy alternates between 2 electrodes situated in a short distance from one another. In the tripolar and multipolar devices, bipolar energy switches between different poles at every moment. The energy is concentrated at the site of treatment and the achieved depth is half of the distance between the two electrodes.

In relation to temperature, it is common to find in the manuals of Brazilian and international equipments that the temperature required for stimulation of collagen synthesis ranges from $50^{\circ} \mathrm{C}$ to $75^{\circ} \mathrm{C}$ in the dermis, and that this temperature is reached when the epidermis remains at $40^{\circ} \mathrm{C}$. However, when looking for studies to substantiate this information, they do not explain this affirmative, leaving doubts about the veracity of the information. Another issue observed is that with the use of international equipments patients need to receive anesthetics to withstand the temperature rise. In the manuals of Brazilian equipments, however, this fact is not mentioned, despite the need to achieve the same therapeutic temperatures. International equipments have a cooling system that protects the epidermis while the dermis is heated and Brazilians devices do not use these systems. ${ }^{13,80}$

The results of this review showed that RF, despite being a commonly used procedure in clinical practice, still needs further study, with analyzes that have both methodological relevance and significant statistical results. Despite the large number of papers on this, most have low methodological quality. According to the literature, good scientific evidence supports the use of new techniques - a fact not found in the present review on RF and skin laxity. ${ }^{81}$

\section{CONCLUSION}

This review allowed to observe that RF acts mainly with the purpose of promoting changes in tissue conformation, inducing neocollagenesis by thermal generation in deep layers of the skin tissue, thus being theoretically suitable for the treatment of wrinkles and skin laxity.

There are a large number of studies being carried out on this subject. However, most studies are not clinical trials with good methodological quality, which prevents decision-making about the effectiveness and the actual role of RF in the treatment of wrinkles and skin laxity.

It is possible that equipments used so far promote the benefits commonly reported by clinical perception. However, if they do occur, mechanisms to explain them are still unknown in scientific circles.

Parameters for adjustment of physiological and therapeutic effects are needed, however the reviewed articles are not clear on the data about temperature as well as the way of measuring the target tissue, the dermis. While there are studies demonstrating the effects of $\mathrm{RF}$, there is a lack of studies specifying the most suitable parameters, especially with respect to power for different tissues. In general, the protocols reported in the literature vary considerably, making definitive conclusions about the most effective parameters extremely difficult.

The use of RF has been based more on marketing than on technical-scientific reasons, as there are a large number of devices available on the market and this number increases every day, without studies with good levels of evidence being carried out. Experimental studies are needed to make an accurate correlation between the temperature of the epidermis and dermis in order to further clarify the effectiveness of RF for the treatment of skin laxity, especially with Brazilian equipments.

Based on the data exposed, it is clear that using $\mathrm{RF}$ for the treatment of skin laxity is still a myth to be clarified and its use should therefore be cautious in the professional practice, especially when the parameters are out of the recommended specifications.] 


\section{REFERENCES}

1. Taieb C, Rahhali N, Moingeon V, Perez-Cullell N, Sibaud V. CosmeceutiQoL: a tool for assessing dermo-cosmetic products' impact on quality of life. J Cosmet Laser Ther. 2012;14:18-23.

2. Mendonça RSC, Rodrigues GBO. As principais alterações dermatológicas em pacientes obesos. ABCD, Arq Bras Cir Dig. 2011;24:68-73.

3. Montagner S, Costa A. Molecular basis of photoaging. An Bras Dermatol. 2009;84:263-9.

4. McCollough EG, Perkins S, Thomas JR. Facelift: Panel Discussion, Controversies, and Techniques. Facial Plast Surg Clin North Am. 2012;20:279-325.

5. Nach R, Zandifar H, Gupta R, Hamilton JS. Subcutaneous carboxytherapy injection for aesthetic improvement of scars. Ear Nose Throat J. 2010;89:64-6.

6. Lee HS, Lee DH, Won $\mathrm{CH}$, Chang HW, Kwon HH, Kim KH, et al. Fractional Rejuvenation Using a Novel Bipolar Radiofrequency System in Asian Skin. Dermatol Surg. 2011;37:1611-9.

7. Brightman L, Goldman MP, Taub AF. Sublative Rejuvenation: Experience With a New Fractional Radiofrequency System for Skin Rejuvenation and Repair. J Drugs Dermatol. 2009;8:s9-13.

8. Bachl N, Ruoff $G$, Wessner $B$, Tschan $H$. Electromagnetic interventions in musculoskeletal disorders. Clin Sports Med. 2008;27:87-105, viii.

9. Anolik R, Chapas AM, Brightman LA, Geronemus RG. Radiofrequency Devices for BodyShaping: A Review and Study of 12 Patients. Semin Cutan Med Surg. 2009;28:236-43.

10. Belenky I, Margulis A, Elman M, Bar-Yosef U, Paun SD. Exploring Channeling Optimized Radiofrequency Energy: a Review of Radiofrequency History and Applications in Esthetic Fields. Adv Ther. 2012;29:249-66.

11. Alster T S, Jason R L. Nonablative cutaneous remodeling using radiofrequency devices. Clin Dermatol. 2007;25:487-91.

12. Harth $Y$, Lischinsky D. A novel method for real-time skin impedance measurement during radiofrequency skin tightening treatments. J Cosmet Dermatol. 2011;10:249.

13. Paasch U, Bodendorf MO, Grunewald S, Simon JC. Skin rejuvenation by radiofrequency therapy: methods, effects and risks. J Dtsch Dermatol Ges. 2009; 7:196-203.

14. Cchs. usyd.edu.au [Internet]. PEDro. Physiotherapy Evidence Database. Escala de PEDro. [cited 2014 Fev 13]. Available from: http://www.cchs.usyd.edu.au/pedro.

15. Reid SA, Rivett DA. A. Manual therapy treatment of cervicogenic dizziness: a systematic review. Man Ther. 2005;10:4-13.

16. Shapiro SD, Eros Y, Abrahami Y, Leviav A. Evaluation of Safety and Efficacy of the TriPollar Technology for Treatment of Wrinkles. Lasers Surg Med. 2012;44:453-8.

17. Abraham MT, Chiang SK, Keller GS, Rawnsley JD, Blackwell KE, Elashoff DA Clinical evaluation of non-ablative radiofrequency facial rejuvenation. J Cosmet Laser Ther. 2004;6:136-44.

18. Rusciani A, Curinga G, Menichini G, Alfano C, Rusciani L. Nonsurgical tightening of skin laxity: a new radiofrequency approach. J Drugs Dermatol. 2007;6:381-6.

19. Hsu TS, Kaminer MS. The Use of Nonablative Radiofrequency Technology to Tighten the Lower Face and Neck. Semin Cutan Med Surg. 2003;22:115-23.

20. Bassichis BA, Dayan S, Thomas JR. Use of a nonablative radiofrequency device to rejuvenate the upper one-third of the face. Otolaryngol Head Neck Surg. 2004; $130: 397-406$

21. el-Domyati M, el-Ammawi TS, Medhat W, Moawad O, Brennan D, Mahoney MG, et al. Radiofrequency facial rejuvenation: Evidence-based effect. J Am Acad Dermatol. 2011;64:524-35.

22. Javate RM, Cruz RT Jr, Khan J, Trakos N, Gordon RE. Nonablative 4-MHz Dual Radiofrequency Wand Rejuvenation Treatment for Periorbital Rhytides and Midface Laxity. Ophthal Plast Reconstr Surg. 2011;27:180-5.

23. Friedman DJ, Gilead LT. The Use of Hybrid Radiofrequency Device for the Treatment of Rhytides and Lax Skin. Dermatol Surg. 2007;33:543-51.

24. Fitzpatrick R, Geronemus R, Goldberg D, Kaminer M, Kilmer S, Ruiz-Esparza J. Multicenter Study of Noninvasive Radiofrequency for Periorbital Tissue Tightening. Lasers Surg Med. 2003;33:232-42.

25. Alster TS, Tanzi E. Improvement of Neck and Cheek Laxity With a Nonablative Radiofrequency Device: A Lifting Experience. Dermatol Surg. 2004;30:503-7.

26. Carruthers J, Carruthers A. Shrinking Upper and Lower Eyelid Skin with a Novel Radiofrequency Tip. Dermatol Surg. 2007;33:802-9.

27. Finzi E, Spangler A. Multipass Vector (Mpave) Technique with Nonablative Radiofrequency to Treat Facial and Neck Laxity. Dermatol Surg. 2005;31:916-22.

28. Kushikata N, Negishi K, Tezuka Y, Takeuchi K, Wakamatsu S. Non-Ablative Skin Tightening With Radiofrequency in Asian Skin. Lasers Surg Med. 2005;36:92-7.

29. Levenberg A. Clinical experience with a TriPollarTradiofrequency system for facial and body aesthetic treatments. Eur J Dermatol. 2010;20:615-9.

30. Montesi G, Calvieri S, Balzani A, Gold MH. Bipolar radiofrequency in the treatment of dermatologic imperfections: clinicopathological and immunohistochemical aspects. J Drugs Dermatol. 2007;6:890-6.
31. Nahm WK, Su TT, Rotunda AM, Moy RL. Objective Changes in Brow Position, Superior Palpebral Crease, Peak Angle of the Eyebrow, and Jowl Surface Area after Volumetric Radiofrequency Treatments to Half of the Face. Dermatol Surg. 2004:30:922-8.

32. Narins DJ, Narins RS. Non-surgical radiofrequency facelift. J Drugs Dermatol. 2003;2:495-500.

33. Ruiz-Esparza J, Gomez JB. The Medical Face Lift: A Noninvasive, Nonsurgical Approach to Tissue Tightening in Facial Skin Using Nonablative Radiofrequency. Dermatol Surg. 2003;29:325-32.

34. Wollina U. Treatment of Facial Skin Laxity by a New Monopolar Radiofrequency Device. J Cutan Aesthet Surg. 2011:4:7-11.

35. Bogle MA, Ubelhoer N, Weiss RA, Mayoral F, Kaminer MS. Evaluation of the Multiple Pass, Low Fluence Algorithm for Radiofrequency Tightening of the Lower Face. Lasers Surg Med. 2007;39:210-7.

36. Fritz M, Counters JT, Zelickson BD. Radiofrequency treatment for middle and lower face laxity. Arch Facial Plast Surg. 2004;6:370-3.

37. Ruiz-Esparza J. Noninvasive lower eyelid blepharoplasty: a new technique using nonablative radiofrequency on periorbital skin. Dermatol Surg. 2004;30:125-9.

38. Kaplan H, Gat A. Clinical and histopathological results following TriPollarT radiofrequency skin treatments. J Cosmet Laser Ther. 2009;11:78-84.

39. Chipps LK, Bentow J, Prather HB, So JJ, Schouest JM, Ozog DM, et al. Novel nonablative radio-frequency rejuvenation device applied to the neck and jowls: clinical evaluation and 3-dimensional image analysis. J Drugs Dermatol. 2013:12:1215-8.

40. Edwards AF, Massaki AB, Fabi S, Goldman M. Clinical Efficacy and Safety Evaluation of a Monopolar Radiofrequency Device with a New Vibration Handpiece for the Treatment of Facial Skin Laxity: A 10-Month Experience with 64 Patients. Dermatol Surg. 2013;39:104-10

41. Suh DH, Lee SJ, Ryou JH, Son HC, Kim HJ, Kim HS. Monopolar Radiofrequency Treatment in Asian Skin: Do Multiple RF Treatments Over Time Have Beneficial Effects? An Observational Report with Long-Term Follow-Up in Eight Patients. Dermatol Surg. 2013;39:670-2.

42. Taub AF, Tucker RD, Palange A. Facial tightening with an advanced 4-MHz monopolar radiofrequency device. J Drugs Dermatol. 2012;11:1288-94.

43. Tay YK, Kwok C. A novel radiofrequency device for the treatment of rhytides and lax skin: A pilot study. J Cosmet Laser Ther. 2009;11:25-8.

44. Vega JM, Bucay VW, Mayoral FA. Prospective, multicenter study to determine the safety and efficacy of a unique radiofrequency device for moderate to severe hand wrinkles. J Drugs Dermatol. 2013;12:24-6.

45. Cec.com.ar [Internet]. Genotherm [cited 2014 Jan 20]. Available from: http:// www.cec.com.ar/br/producto-detalle.php?producto $=108 \&$ rubro $=23$.

46. Fundarbrasil.com.br [Internet]. Genesis. [cited 2014 Jan 20]. Available from: http://www.fundarbrasil.com.br/genesis/

47. Cec.com.ar [Internet]. Triaterm. [cited 2014 Jan 20]. Available from: http://www. cec.com.ar/br/producto-detalle.php?producto $=107 \&$ rubro $=23$

48. meditea.com [Internet]. Splenda. [cited 2014 Jan 20]. Available from: http://www. meditea.com/productos/radiofrecuencia/splenda-70.html

49. Meditea.com [Internet]. Innovater. [cited 2014 Jan 19]. Available from: http:// www.meditea.com/productos/radiofrecuencia/rf-innovater-45.html

50. Topcavity. Com [Internet]. Sobre o Top Cavity. [acesso 20 jan 2014]. Disponível em: http://www.topcavity.com/sobre.php?page = sobre

51. Estetica-libela.com [Internet]. RADIOFREQUÊNCIA (Photogen System) é um aparelho médico estético que elimina RUGAS, FLACIDEZ, CELULITE... obtendo resultados espectaculares desde a $1^{\text {a }}$ sessão [acesso 22 jan 2014]. Disponível em: http://www.estetica-libela.com/radiofrequencia.pdf

52. Pelleve. [Internet]. Pelleve RF Wrinkle Reduction [acesso 20 jan 2014]. Disponível em: http://www.pelleve.com/.

53. Meditea.com [Internet]. Multicel [acesso 25 jan 2014]. Disponível em: http:// www.meditea.com/productos/radiofrecuencia/multicel-46.html

54. Thermaccol.com [Internet]. Thermage Science [acesso 20 jan 2014]. Disponível em: http://www.thermage.com/

55. Skintecmedical.com.br [Internet]. Freeze. [acesso 25 jan 2014]. Disponível em: http://www.skintecmedical.com.br/Equipamento.aspx?id=1202

56. VelaShape.com [Internet]. How VelaShape Works [cited 2014 Jan 24]. Available from: http://www.velashape.com/how-velashape-works

57. Ibramed.com.br [Internet]. Hooke. [acesso 20 jan 2014]. Disponível em: http:// www.ibramed.com.br/site/upload/produtos_73_manual_pt.pdf

58. Kld.com.br [Internet]. Hertix. [acesso 20 jan 2014]. Disponível em:http://www. kld.com.br/pt/downloads.aspx

59. Tonederm.com.br [Internet]. Spectra. [acesso 19 jan 2014]. Disponível em: http:// www.tonederm.com.br/beauty/produtos int.php?id $=15 \&$ categoria $=6$

60. shopfisiobrasil.com.br [Internet]. Bioset. Manual do usuário [acesso 22 jan 2014]. Disponível em:http://www.shopfisiobrasil.com.br/pdf/1652.pdf

61. Steticline.com.br [Internet]. Light Plus. [acesso 20 jan 2014]. Disponível em: 
http://www.steticline.com.br/site/index.php/rf-light-plus/

62. Hv.com.br [Internet]. Apollo TriPollar ${ }^{\circledR}$ Radiofrequência de terceira geração. [acesso 25 jan 2014]. Disponível em: http://www.hv.com.br/medical/Radio_ Tripollar.html

63. Steticline.com.br [Internet]. RF Light Plus. [acesso 25 jan 2014].Disponível em: http://www.steticline.com.br/site/index.php/rf-light-plus/

64. Kligman LH. Skin changes in photoaging: Characteristics, prevention, and repair Aging and the skin. New York: Raven Press; 1989. p. 331-346.

65. Brinckmann J, Bodo M, Brey M, Wolff HH, Müller PK. Analysis of the age-related composition of human skin collagen and collagens synthesized by fibroblast culture. Arch Dermatol Res. 1994;286:391-5.

66. Goodman R, Blank M. Insights Into Electromagnetic Interaction Mechanisms. J Cell Physiol. 2002;192:16-22.

67. Tokalov SV, Gutzeit HO. Weak electromagnetic fields $(50 \mathrm{~Hz})$ elicit a stress response in human cells. Environ Res. 2004;94:145-51.

68. Alvarez N, Ortiz L, Vicente V, Alcaraz M, Sánchez-Pedreño P. The Effects of Radiofrequency on Skin: Experimental Study. Lasers Surg Med. 2008;40:76-82.

69. Arnoczky SP, Aksan A. Thermal modification of connective tissues: basic science considerations and clinical implications. J Am Acad Orthop Surg. 2000;8:305-13.

70. Zelickson BD, Kist D, Bernstein E, Brown DB, Ksenzenko S, Burns J, et al. Histological and Ultrastructural Evaluation of the Effects of a RadiofrequencyBased Nonablative Dermal Remodeling Device. Arch Dermatol. 2004;140:204-9.

71. Ahmadian S, Zarchi SR, Bolouri B. Efects of extremelylow-frequency pulsed electromagnetic fields on collagen synthesis in rat skin. Biotechnol Appl Biochem. 2006;43:71-5.

72. Elsaie ML, Choudhary S, Leiva A, Nouri K. Nonablative Radiofrequency for Skin Rejuvenation. Dermatol Surg. 2010;36:577-89.

73. Abraham MT, Mashkevich G. Monopolar Radiofrequency Skin Tightening. Facial Plast Surg Clin North Am. 2007;15:169-77, v.
74. Biesman B. S. Advances in technology-based eyelid skin rejuvenation. Cosmet Dermatol. 2007;20:751-6.

75. Atiyeh BS, Dibo SA. Nonsurgical nonablative treatment of aging skin radiofrequency technologies between aggressive marketing and evidence-based efficacy. Aesthetic Plast Surg. 2009;33:283-94.

76. Darden EB Jr, Upton AC. Temperature of maximum contraction of mouse collagen fibers as influenced by aging, x-radiation, and breeding status. J Gerontol. 1964;19:62-5.

77. Hayashi K, Thabit G 3rd, Massa KL, Bogdanske JJ, Cooley AJ, Orwin JF, et al. The effect of thermal heating on the length and histologic properties of the glenohumeral joint capsule. Am J Sports Med. 1997;25:107-12

78. Naseef GS 3rd, Foster TE, Trauner K, Solhpour S, Anderson RR, Zarins B. The thermal properties of bovine joint capsule: The basic science of laser and radiofrequency-induced capsular shrinkage. Am J Sports Med. 1997;25:670-4.

79. Tunnell JW, Pham L, Stern RA, Pope KA. Mathematical model of non-ablative RF heating of skin (Poster). Lasers Surg Med. 2002;30:58-87.

80. Polder KD, Bruce S. Radiofrequency: Thermage. Facial Plast Surg Clin North Am. 2011:19:347-59.

81. Moseley AM, Herbert RD, Sherrington C, Maher CG. Evidence for physiotherapy practice: A survey of the Physiotherapy Evidence Database (PEDro). Aust $\mathrm{J}$ Physiother. 2002;48:43-9.

\author{
MAILING ADDRESS: \\ Angélica Rodrigues de Araújo \\ Instituto de Ciências Biológicas e da Saúde/ Departamento \\ de Fisioterapia - PUC-Minas \\ 500, Dom José Gaspar Av. \\ Coração Eucarístico \\ 30535-901 - Belo Horizonte - MG \\ Brazil \\ Email:angelica@bios.srv.br
}

How to cite this article: Araújo AR, Soares VPC, Silva FS, Moreira TS. Radiofrequency for the treatment of skin laxity: mith or truth. An Bras Dermatol. 2015;90(5):707-21. 